\title{
2009, The Year Of Diversification
}

\author{
Hamid Ahmadi, Ph.D., California State University, Sacramento, USA
}

\begin{abstract}
Today, no company is safe, no industry is secure, no rating is impartial, no advisor is certain, and no country is immune from economic and financial malaise. The days of optimistically believing the advisors and benefiting from investment in equity markets are long gone. Any recommended asset or a strategy is questioned and everywhere doubts outdo trust. In these financial dark days, however, few things are still true: rational and logical approaches endure, sound and understandable assumptions hold, diversification works.

Diversification is a simple and yet powerful commonsensical approach to investment. It is easy to do and it works well for small and large portfolios with few or many assets. If one chooses to use diversifications techniques, an important question to ask is whether it is based on data across all time-periods, or over primarily down markets when diversification is most valuable. This study examines the performance of a well-diversified portfolio and compares the results with the performance of other portfolios including an equally-weighted equity portfolio over the down market from April 2, 2007 to April 4, 2009.

Although there still exits a sense of uneasiness in the stock market about equity investing, the above average rate of returns and steady growth of diversified portfolios over the past two troubling years compels investors to consider diversifications again. The main goal of this work is to first examine the performance of several companies and compare their risk-adjusted returns to the returns of indexes, mainly $S \& P$ 500, and then compare the performance of a well-diversified portfolio with a balanced equity portfolio. Specifically, this study is going to address whether the performance of a well-diversified portfolio meets or surpasses the performance of a diversified equally weighted portfolio. More importantly the emphasis of this work is to determine whether diversification consistently and significantly contributes positively to the performance of the US equity portfolios. The asset selection and the optimization process applied to portfolios are identical to maintain consistency and comparability of the results. For each portfolio we used the 2005-2007 daily observations to optimize allocations and we used the 2007-2009 data to evaluate the performance of each portfolio.
\end{abstract}

\section{INTRODUCTION}

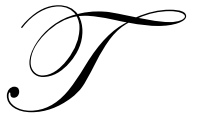

he sub-prime crisis of 2008 has led to significant reductions in returns of all major stocks within the U.S. equity market. The financial market has been especially hard hit. Once housing prices started to drop moderately in 2006-2007 in many parts of the U.S., refinancing became more difficult. Defaults and foreclosures increased dramatically as Adjustable Rate Mortgage (ARM) interest rates reset higher. During 2008, nearly 2.3 million U.S. housing properties were subject to foreclosure activity, up $79 \%$ from 2007 . The Economist estimated subprime defaults would surpass $\$ 300$ billion. Falling U.S. housing prices and rising delinquencies in mortgage-market losses, including securities tied to commercial real estate and loans to consumers and companies, may reach $\$ 945$ billion according to the IMF. The financial-services industry has posted losses of $\$ 1.2$ trillion since July of 2007, while Prices of U.S. single-family homes plunged 18.5 percent in December 2008 from a year earlier, according to a Standard \& Poor's/Case-Shiller home price index.

The financial problems of 2008 set off a major crisis in virtually all financial sectors, and by all accounts the U.S. Equity Market has been severely affected. Academically, however, this downturn has also provided an opportunity to study and test what investment strategy would optimize the performance of an equity portfolio. Using ex-post data, this research examines the implications and benefits of employing Risk-Adjusted Modeled Portfolio (RAMP Model) allocation process to different size portfolios before and during the current financial crisis. This 
study compares the returns of optimally weighted portfolios to equally weighted portfolios and against the S\&P 500 Index. In this work we have evaluated the performance of a well diversified portfolio and matched its performance against that of similar portfolios in market. The results were striking. We found that the annualized risk-adjusted rate of return for an optimized portfolio was significantly higher than that of S\&P 500 and well above an equallyweighted portfolio. The purpose of this research is to determine whether the RAMP Model provides superior results when compared to the S\&P 500 Index before and during the current financial crisis. Such a model will prescribe not only the optimal number of assets to hold in a portfolio, but it also computes the optimal weights of each asset in an optimal portfolio.

\section{DATA AND RESEARCH DESIGN}

The data for this research consists of 4 years of ex post daily prices and dividends from August 5, 2005 to February 5, 2009 for 45 companies from various stock exchanges and a pool of over 90 stocks that were listed in the New York Stock Exchange (NYSE). While there were many stocks from the total population that had daily return data going back four years, many of those stocks had "thin" trading histories. This resulted in a significant variation in returns due to the small number of shares traded for any given observation. The 45 stocks selected were based on their relative trading strength and their price availability over the past four years. It was found that these stocks had over 1,000,000 shares traded on the various trading days.

The equations in the next section describe how the various monthly return data (based on daily price and dividend data) was calculated for each of the various sized asset portfolios ranging from 3 assets to 30 assets. As Table 1 indicates, the research design initially uses the first 20 months of daily observations from August 5, 2005 to April 2, 2007 to determine average returns, standard deviation and correlation values for each of the stocks in the sample. Then, from April 2, 2007 to February 5, 2009 portfolios were formed with optimal weights based on the statistics and information generated from the first 20 months.

Table 1: Summary of Data Selection

\begin{tabular}{|c|c|}
\hline \multicolumn{2}{|c|}{ Data-Model Specifications } \\
\hline Data Daily Obsrvation From: & August 5, 2005 \\
\hline Data Daily Obsrvation To: & February 5, 2009 \\
\hline Optimization Methods & MVP, RAMP, Equal-weights \\
\hline \# of Observations to Optimize & 40 \\
\hline Optimization Rebalancing Freq. & BiWeekly \\
\hline Market & S\&P 500 \\
\hline
\end{tabular}

\section{LITERATURE REVIEW}

The efficiency of portfolios has been a topic for debate over the last twenty plus years within the body of finance literature. Depending on time periods analyzed and types of assets invested in, the answer to efficiency varies. However, the implications for investment opportunity abound if it can be demonstrated that funds either are or are not efficiently priced assets. If individual assets are less than efficiently priced then a strategy application of efficiently selecting these assets using modern portfolio analysis would tend to be financially rewarding. In this section, we examine selected articles that relate first to the efficiency of asset prices and then secondly to the application and impact of efficient portfolio selection processes to obtain superior returns.

Chen, Ho, Lu, and $\mathrm{Wu}(2005)$ examine whether the addition of real estate assets can significantly expand the mean-variance efficient frontier beyond stocks that are already publicly traded, to provide substantial diversification benefits for investors or fund managers, is an intriguing question. Results of this study indicate that REITs before 1985 are unable to provide additional diversification benefits. However, more recent REITs over the period from 1986-2002 do improve the mean-variance frontier and expand the investment opportunity set. 
Salter (2006) tested the relative risk-adjusted performance of assets using both a naïve and optimal portfolio allocation strategy. The results of this study indicate that a scientific statistical approach to portfolio selection, dominates naïve methods (i.e. equally weighted) methods for the time period considered from 1995 to 2005. In addition to Markowitz optimization, the author also uses stochastic dominance, which is shown to produce the greatest growth in capital on a non-risk adjusted basis.

Anderson and Springer (2003) develop a portfolio asset selection model based on operating efficiency and pricing multiples. Portfolios are constructed that exhibit relatively high operating efficiency, trading at low prices. The results of this research indicate that these pre-screened portfolios have superior performance during the first year of selection. Further superior performance also ensued in years 2 and three, suggesting there are potential rewards for investing in funds through a pre-screening process and then using efficient portfolio selection techniques in indentifying superior performing portfolios.

Using monthly real estate funds data from the National Association of Real Estate Investment Trusts, Inc. (NAREIT), Jirasakuldech and Knight (2005) test the efficiency of Real Estate Investment Trusts (REITs) markets from 1972 to 2004. The data is segmented chronologically to take into account the effect of the Tax Reform Act of 1986 and the effect of the explosive growth in market capitalization that began in the early 1990s.

Stevenson (2002) examines the out-of-sample performance of Equity portfolios based on market sectors, with the aim of examining the potential improvements in performance resulting from alternative methods designed to reduce estimation error. The results indicate the best performing portfolio is not the "Minimum Variance Portfolio" (MVP) but alternative tangency portfolios. This occurs despite the instability in the estimated allocations, the presence of corner solutions and the frequent large shifts in the weights. Ahmadi, H., Galindo, C. (2005) in "Two Staged Portfolio Optimizations"; and Ahmadi, H. \& Soriano B. (2003) in "An Analytical Technique for Determining Efficient Portfolios" validate this hypothesis.

In addition to the articles cited above, a number of other studies have been conducted and are relevant to this current research. These include articles on issues of REIT efficiency, asset allocation, and Markowitz optimization. The following list includes conducted research on many of these topics: Addae-Dapaah, Wee, and Ebrahim (2002), Booth (2002), Stevenson (2002), Tse (2002), Lewis, Springer, and Anderson (2003), Chui, Titman, and Wei (2003), Chen, Ho, Wu, and Lu (2005), among others. Since it is not possible to discuss these works in detail in this study, the above list is offered as partial treatment of the relevant topics that impact this current research.

\section{DATA AND SELECTION CRITERIA}

In this study, our goal is to evaluate the performance of several distinct portfolios. The components of each portfolio, albeit different, were selected based on a thorough analysis of individual assets. The selection of the assets for either portfolio was exhaustive relying on various reputable data sources reporting financial characteristics of each stock. The specific criteria for selecting an asset in all portfolios are volume, P/E ratio, return on equity, positive returns and data sufficiency. One of the most important indicators for liquidity is volume of trade. Low volume signals the possibility of sudden price movements due to a small shift in demand for that stock. Thus, we considered stocks with large trading volume to avoid daily swings in security prices. We compared the return on equity (ROE) of each asset with the ROE of its industry, selecting only those assets that historically outperformed

the industry. Companies with unusually high P/E ratios and those with missing P/E data were excluded. The above process ensures application of similar criteria to both foreign and U.S. stocks and includes only well established companies with solid records.

\section{THE MODEL}

There are three common approaches to portfolio optimization - the Equal Weights (EW) approach, the Minimum Variance Portfolio (MVP) approach, and the Modern Portfolio Theory (MPT) approach. While each of these methods can help a portfolio manager respond to his clients' needs, there is an additional approach that can be used to generate an optimal portfolio - the Risk-Adjusted Managed Portfolio (RAMP) model. While the MVP and 
MPT approaches rely on variance to determine risk and help portfolio managers determine whether to buy or sell a particular asset, RAMP considers beta and variance. Specifically, RAMP is a two-stage model that provides us with a simple, but effective means of selecting stocks and determining the appropriate proportions of each to hold in our portfolio. The first stage of the RAMP model uses the Treynor Index to help us select stocks for our portfolio, while the second stage uses the Sharpe Index to determine what proportion of our portfolio should be invested in each stock.

\section{Stage 1 -Stock Selection}

Since we need to determine which stocks to include in our optimal portfolio, the first stage of the RAMP model assists us with stock selection. Of course, it would be very easy to form such a portfolio if there were a single number we could use to decide whether or not to include a particular stock in the portfolio. The RAMP optimization model finds this key number and tells us to include in our portfolio any stock with a Treynor Index that exceeds it.

TreynorIndex $=\frac{\left(R_{j}-R_{f}\right)}{\beta_{j}}$

Where $R_{j}$ is the rate of return for stock " $\mathrm{j}$," $R_{f}$ is the risk-free rate of return and $B_{j}$ is the beta value for stock " $\mathrm{j}$ ”. Note that both the market rate of return $\left(R_{m}\right)$ and the risk-free rate of return $\left(R_{f}\right)$ result from general stock market fluctuations and are not due to the work of a portfolio manager. In other words, $\left(R_{m}-R_{f}\right)$ is the return of an "unmanaged portfolio". If the Treynor Index $\frac{\left(R_{j}-R_{f}\right)}{\beta_{j}}$, which is the risk-adjusted return of stock $j$, is greater than $\left(R_{m}-R_{f}\right)$, then stock $j$ outperformed the unmanaged market portfolio and stock $j$ is a candidate to be included in our optimal portfolio. Once again, the general rule for including or excluding stocks from our optimal portfolio is to include the stock if its Treynor Index is greater than the key number calculated by RAMP. We will call this key number the cut-off number.

\section{Stage 2 - Determining Optimal Proportions}

Inclusion and exclusion of stocks is the first part of the RAMP model. The second task is to find the proportions to be invested in each included stock in order to create an optimal portfolio. This optimization process is similar to MPT in that the proportions of the market portfolio, or Portfolio M, are determined by maximizing the slope of the Capital Market Line (CML). In other words, we hold stocks in the proportions dictated by the maximum Sharpe Index.

In summary, the RAMP model compares a stock's risk-adjusted return (as measured by the Treynor Index) with the cut-off number mentioned above to determine whether to include the stock in our portfolio. It then uses the Sharpe Index to find the proportion of funds to be invested in each stock in order to create an optimal portfolio. Thus, the optimal portfolio we select using the RAMP model will not only have passed the Treynor Index test, but will also have secured the highest possible return at any given level of risk.

\section{Rebalancing}

An investor must also pay close attention to rebalancing, which is the periodic adjustment of the proportion of the portfolio invested in each asset. Rebalancing is a means of maintaining the optimal asset mix within the portfolio through purchase and sale of individual assets. After an investor decides how to allocate his or her assets, the decision as to what portfolio rebalancing strategy to use is probably the most important factor in creating and maintaining a successful portfolio. As the economic environment and market conditions change, investors must rebalance their portfolios to incorporate current and relevant information into their asset allocation processes.

So how often a portfolio should be rebalanced? The answer to this question is partially subjective and partially determined by factors such as the type of investment strategy and the amount of work required of portfolio 
managers in the rebalancing process. In general, we can distinguish between the following two approaches to portfolio rebalancing:

1. Calendar Rebalancing: Rebalancing the portfolio to its optimal allocation at a certain frequency such as weekly, biweekly, monthly, quarterly, etc.

2. Threshold Rebalancing: Rebalancing the portfolio to its optimal allocation once it exceeds a certain range. For example, the portfolio could be rebalanced when the portfolio weights differ by more than ten percent from the optimal weights.

\section{Parameters}

Our data consists of daily observations from August 5, 2005 to April 4, 2009. We split the data into two parts: 1) observations from August 5, 2005 to April 2, 2007; and 2) observations from April 2, 2007 to April 4, 2009. The first part is used to compute inputs for the models and the second part is used to track the performance of the portfolios each month. As mentioned above, the RAMP model includes a stock if its Treynor Index is greater than a cut-off number. One of the inputs to the Treynor Index is the risk-free rate and in this study we use an aggregate rate of 3 percent for this parameter. Also, we selected the option to pay 2 percent money market rate to the unused cash in the account.

\section{RESULTS}

The results of our study show that from April 2007 to April 2009, on average, the return of the well diversified world asset portfolio was 32.20 percent higher than the return of the S\&P 500. Furthermore, during this period, on average, the return of this portfolio was 23.02 percent higher than the return of an equally weighted portfolio of U.S. stocks. The performance of each portfolio, along with the difference is presented in Table 2 and Graph 1 below. Graph 1 displays the performance of portfolios formed by the RAMP model and other techniques verses S\&P 500. The results clearly demonstrate that the portfolio formed by RAMP model significantly outperformed other portfolios during the 2008 down market. It is important to note that the returns of all portfolios are standardized and adjusted for risk to make comparisons possible. That is, the graph below reports the riskadjusted returns for all portfolios so that a portfolio's performance can be compared with the performance of other portfolios and the stock market.

Table 2: Cumulative Returns from 2007 to 2009

\begin{tabular}{|c|c|c|c|c|c|}
\hline \multicolumn{6}{|c|}{ CUMMULATIVE RETURNS STARTING 4/2/2007 } \\
\hline Date & RAMP & SP500 & Date & RAMP & SP500 \\
\hline April 16, 2007 & $1.93 \%$ & $4.73 \%$ & April 14, 2008 & $12.70 \%$ & $-5.26 \%$ \\
\hline May 14,2007 & $5.02 \%$ & $7.21 \%$ & March 31, 2008 & $10.97 \%$ & $-5.66 \%$ \\
\hline June 11,2007 & $6.37 \%$ & $7.64 \%$ & May 12,2008 & $16.99 \%$ & $0.11 \%$ \\
\hline July 9, 2007 & $7.31 \%$ & $9.26 \%$ & June 9, 2008 & $13.50 \%$ & $-2.87 \%$ \\
\hline August 6, 2007 & $5.94 \%$ & $4.68 \%$ & July 7, 2008 & $.96 \%$ & $-10.68 \%$ \\
\hline September 4, 2007 & $6.02 \%$ & $6.23 \%$ & August 4, 2008 & $6.92 \%$ & $-10.92 \%$ \\
\hline October 1, 2007 & $10.21 \%$ & $10.34 \%$ & September 2, 2008 & $8.99 \%$ & $-8.88 \%$ \\
\hline October 29, 2007 & $11.12 \%$ & $9.91 \%$ & September $29,200 \$$ & $4.08 \%$ & $-21.09 \%$ \\
\hline November 26, 2007 & $7.57 \%$ & $0.37 \%$ & October 27, 2008 & $-8.15 \%$ & $-39.45 \%$ \\
\hline December 24, 2007 & $13.43 \%$ & $6.73 \%$ & November $24,200 \$$ & $-6.06 \%$ & $-39.25 \%$ \\
\hline January 22, 2008 & $7.45 \%$ & $-6.53 \%$ & December 22, 2008 & $-3.04 \%$ & $-37.83 \%$ \\
\hline February 19, 2008 & $9.24 \%$ & $-3.80 \%$ & January 20, 2009 & $-4.55 \%$ & $-42.57 \%$ \\
\hline March 17, 2008 & $9.32 \%$ & $-8.95 \%$ & February 2, 2009 & $-8.93 \%$ & $-41.13 \%$ \\
\hline
\end{tabular}




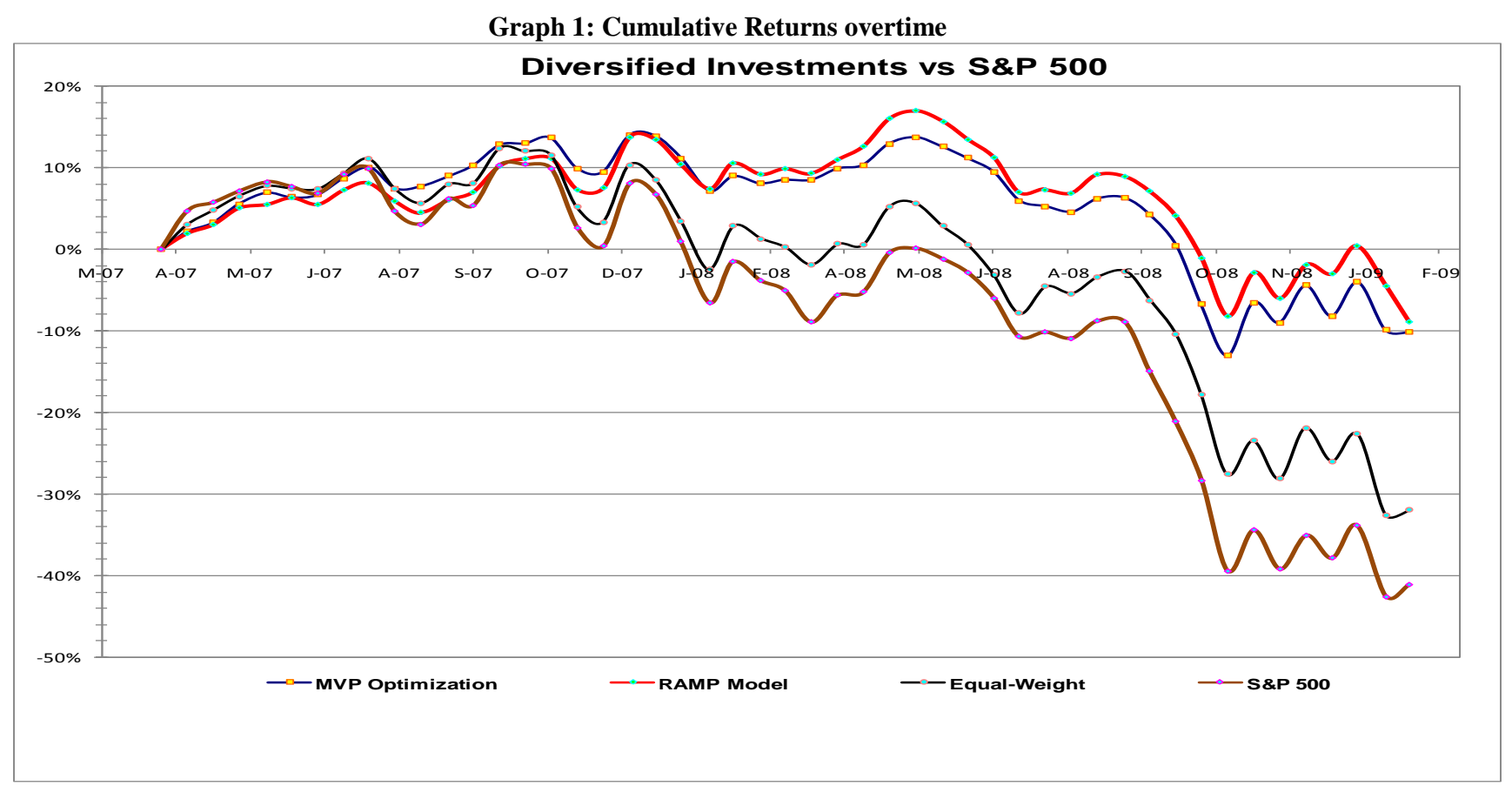

The premise of this work is not to show the superiority or the weaknesses of the RAMP model. It is to examine the performance of two diversified portfolios over current down market. To make our results independent of any optimization model, we decided to test the results by using Equal Weight approach. That means we assigned equal weight to each asset to form a neutral portfolio for comparisons purposes.

\section{THE CONCLUSIONS}

Although the equity market lost popularity in the last two years, this work presents unambiguous results supporting the outstanding performance of the RAMP diversification model over the current financial period. Specifically, this study addressed the question of performance of a diversified portfolio over a down market and showed that employing risk adjusted modeled allocation process consistently and significantly outperformed the S\&P 500 index. These results are based on data from March 2005 to September 2008. The results were striking. To be precise, they show that from April 2007 to April 2009 the return of the well diversified portfolio was 32.20 percent higher than the return of the U.S. equity benchmark.

Table 3 shows the components of the optimized portfolio in March 2009.

\section{QUALIFICATIONS}

It is important to note that the outcome of this research is specific to the assets that were included in each portfolio and during the period in which this study was conducted. Due to changing economic conditions in the U.S. and throughout the world, the results may be different for future portfolios. In addition, as equity market becomes more volatile, such results may not hold due to greater imbalances and global market inefficiency.

Future studies need to reexamine this question and repeat this work to confirm the consistency of our results over a longer time period. Additionally, we believe that there are many reputable global companies as ADR listing can be included in future research. Thus, future studies need to include these companies in their global portfolios. 
Table 3: Components of an Optimal Portfolio in 2009

\begin{tabular}{|c|c|c|c|c|c|}
\hline \multicolumn{6}{|c|}{ Data as of March 6, 2009} \\
\hline Symbol & Company Name & Price & $\begin{array}{c}\text { Market } \\
\text { Cap: }\end{array}$ & P/E Ratio & $\begin{array}{c}\text { Dividend } \\
\text { \& Yield }\end{array}$ \\
\hline cvx & CHEVRON CORP & $\$ 56$ & \$123.35B & 5 & $\begin{array}{c}\$ 2.60 \\
(4.30 \%) \\
\end{array}$ \\
\hline XOM & EXXON MOBIL CP & $\$ 57$ & \$337.87B & $\mathbf{8}$ & $\begin{array}{c}1.60 \\
(2.40 \%)\end{array}$ \\
\hline BA & BOEING CO & $\$ 29$ & \$22.83B & 9 & $\begin{array}{c}\$ 1.68 \\
(5.30 \%) \\
\end{array}$ \\
\hline HPQ & HEWLETT PACKARD CO & \$27 & $\$ 69.96 B$ & 9 & $\begin{array}{c}0.32 \\
(1.10 \%)\end{array}$ \\
\hline ммм & 3M COMPANY & $\$ 42$ & \$31.54B & 9 & $\begin{array}{c}2.04 \\
(4.50 \%)\end{array}$ \\
\hline PFE & PFZER INC & $\$ 12$ & \$83.01B & 10 & $\begin{array}{c}\$ 1.28 \\
(10.40 \%)\end{array}$ \\
\hline $\mathbf{T}$ & AT\&T INC & $\mathbf{\$ 2 3}$ & $\$ 140.08 B$ & 11 & $\begin{array}{c}1.64 \\
(6.90 \%)\end{array}$ \\
\hline PG & PROCTER GAMBIE CO & $\$ 45$ & \$141.18B & 11 & $\begin{array}{c}\$ 1.60 \\
(3.30 \%)\end{array}$ \\
\hline $\mathbf{V Z}$ & VERIZON COMMUN & \$23 & \$81.04B & 13 & $\begin{array}{c}1.84 \\
(6.40 \%) \\
\end{array}$ \\
\hline MCD & MCDONALDS CP & $\$ 46$ & \$58.23B & 14 & $\begin{array}{c}\mathbf{\$ 2 . 0 0} \\
(3.80 \%)\end{array}$ \\
\hline HD & HOME DEPOT INC & \$17 & \$35.12B & 16 & $\begin{array}{c}\$ 0.90 \\
(4.30 \%) \\
\end{array}$ \\
\hline JPM & JP MORGAN CHASE CO & \$18 & \$85.29B & 17 & $\begin{array}{c}0.20 \\
(0.90 \%)\end{array}$ \\
\hline
\end{tabular}

\section{AUTHOR INFORMATION}

Hamid Ahmadi, Ph.D. Professor of Finance: While being professor of Finance at the Sacramento State University, Ahmadi had an opportunity to be a visiting scholar at the Stanford University. He has also held visiting professorships at the Thammasat University in Bangkok Thailand. Ahmadi's primary research interest is in assetallocations, both in the U.S. and abroad. He has written extensively on portfolio management in the United States and also other industrial, but less developed economies. Currently he is studying the relationship between performance of investment portfolios using mathematical modern portfolio theories in comparison with less technical approaches to investments and the empirical relationship between optimization and fundamentals. Professor Ahmadi has taught Portfolio Theory, Security Analysis and Portfolio Management, Advanced Investment Strategies, and Financial Institutions and Markets.

\section{REFERENCES}

1. Addae-Dapaah, K., S.G. Wee, and M.S. Ebrahim. Real Estate Portfolio Diversification by Sources of Return. Journal of Real Estate Portfolio Management, 2002, Volume 8, Issue 1; pp. 1-15.

2. Ahearne, A., Griever, W., \& Warnock, F. (2004). "Information Costs and Home Bias: an Analysis of U. S. Holdings of Foreign Equities". Journal of International Economics.

3. Ahmadi, H., Khoroujik, J (2007). "Do Under-Managed Portfolios Outperform Over-Managed Portfolios?" Journal of Business \& Economics Research. Volume 5, number 4.

4. Ahmadi, H., Galindo, C. (2005). "Two Staged Portfolio Optimizations". Journal of Business \& Economics Research. Volume 3, number 4.

5. Ahmadi, H. \& Soriano B. C. (2003). "An Analytical Technique for Determining Efficient Portfolios". American Academy of Accounting and Finance. Proceedings. 
6. Ahmadi, H. (1996). "Testability of Arbitrage Pricing Theory by Neural Networks". Neural Networks in Finance and Investments. Probus Publishing Company, Chicago.

7. Anderson Randy I, Thomas M Springer. REIT selection and portfolio construction: Using operating efficiency as an indicator of performance. Journal of Real Estate Portfolio Management. Boston: JanuaryApril 2003. Volume 9, Issue 1; pp. 17-28.

8. Booth, P.M. Real Estate Investment in an Asset/Liability Modeling Context. Journa of Real Estate Portfolio Management, 2002, Volume 8, Issue 1; pp. 183-98.

9. Chen, Hsuan-Chi, Keng-Yu Ho, Chiuling Lu, Cheng-Huan Wu. Real Estate Investment Trusts: An Asset Allocation Perspective. Journal of Portfolio Management. Special Real Estate Issue. September 2005. pp. 46.

10. Chui, A.C.W., S. Titman, and K.C. Wei. The Cross Section of Expected REIT Returns. Real Estate Economics, 2003, Volume 31, Issue 3; pp. 451-479.

11. Dahlquist, M., Rinkowitz, L., Stulz, R., \& Williamson, R. (2003). “Corporate Governance and the Home Bias”. Journal of Financial and Quantitative Analysis, 38, 87-110.

12. Fang, H. \& Loo, J. C. H. (2002). "Pricing of American Depository Receipts under Market Segmentation". Global Finance Journal, 13.2, 237-252.

13. Jirasakuldech Benjamas, John R Knight. Efficiency in the Market for REITs: Further Evidence. Journal of Real Estate Portfolio Management. Boston: May-August 2005. Vol.11, Issue 2; p. 123-133.

14. Khoroujik, J., \& Ahmadi, H. (2007). "The Empirical Evidence Conclusively Supports Global Investing." International Business \& Economics Research Journal. Volume 6, Number1.

15. Schaub, M. (2006). "Short-term Investor Wealth Effects Associated with NASDAQ-traded ADRs: the Cases of Emerging, Developed, and Regional issues”. Journal of Wealth Management, v8 i4.

16. Schaub, M. \& Highfield, M. (2006). "Market Timing Wealth Effects of American Depository Receipts: The Cases of Emerging and Developed Market Issues". Journal of International Financial Markets, Institutions \& Money, 16.

17. Foerster, S. R. \& Karolyi, A.. G. (2000). "The Long-run Performance of Global Equity Offerings". Journal of Financial and Quantitative Analysis. 35.4.

18. Kao, G., Wenchi K. C., Wei, J., \& Vu, J. (1991). "Risk-Return Characteristics of the American Depository Receipts". Unpublished Working Paper.

19. Lewis, D., T.M. Springer, and R.I. Anderson. The Cost Efficiency of Teal Estate Investment Trust; An Analysis with a Bayesian Stochastic Frontier Model. Journal of Real Estate Finance and Economics, 2003, Volume 26, Issue 1; pp. 65-80.

20. Parker Hall III, J. (2005, May-June). “Good News!” Financial Analysts Journal, Vol. 61, No.3: 42

21. Ritter, J. (1988, July). "The Buying and Selling Behavior of Individual Investors at the Turn of the Year." Journal of Finance, Vol. 43, 701-17.

22. Salter Sean P, NASDAQ REITs and Optimal Investment Policy: Evidence from 1995 to 2005. Journal of Real Estate Portfolio Management; September-December 2006, Volume 12, Issue 3; pp. 201-207.

23. Stevenson Simon. Ex-ante and ex-post performance of optimal REIT portfolios Journal of Real Estate Portfolio Management. Boston: Sep-Dec 2002. Volume 8, Issue 3; pp. 199-207.

24. Tse, R.Y.C. Price-Earnings Ratios, Dividend Yields and Real Estate Stock Prices. Journal of Real Estate Portfolio Management, 2002, Volume 8, Issue 2; pp. 107-113. 